\title{
OS MISTÉRIOS QUE CIRCUNDAM A DOENÇA DE KAWASAKI: UMA REVISÃO DE LITERATURA
}

\section{ARTIGO ORIGINAL}

ROSSI, Karoline ${ }^{1}$, MOREIRA, Danilo José Silva ${ }^{2}$, FONSECA, Juliana Brito da ${ }^{3}$, VASCONCELOS, Suzana dos Santos ${ }^{4}$, OLIVEIRA, Vinicius Faustino Lima de ${ }^{5}$, DIAS, Claudio Alberto Gellis de Mattos ${ }^{6}$, OLIVEIRA, Euzébio de ${ }^{7}$, DENDASCK, Carla Viana $^{8}$, ARAÚJO, Maria Helena Mendonça de ${ }^{9}$, FECURY, Amanda Alves ${ }^{10}$

ROSSI, Karoline. Et al. Os mistérios que circundam a doença de Kawasaki: uma revisão de literatura. Revista Científica Multidisciplinar Núcleo do Conhecimento. Ano 06, Ed. 04, Vol. 05, pp. 52-64. Abril. ISSN: 2448-0959, Link de acesso: https://www.nucleodoconhecimento.com.br/saude/doenca-de-kawasaki, DOI: 10.32749/nucleodoconhecimento.com.br/saude/doenca-de-kawasaki

\section{RESUMO}

A doença de Kawasaki (DK) ou Síndrome de Linfonodos Mucocutâneos é uma vasculite sistêmica, a qual acomete principalmente crianças menores de cinco anos de idade com descendência asiática, mas também pode atingir outras faixas etárias, assim como qualquer outra raça. O quadro clínico da DK possui três estágios:

\footnotetext{
${ }^{1}$ Acadêmica de Medicina. Universidade Federal do Amapá (UNIFAP).

${ }^{2}$ Acadêmico de Medicina. Universidade Federal do Amapá (UNIFAP).

${ }^{3}$ Acadêmica de Medicina. Universidade Federal do Amapá (UNIFAP).

${ }^{4}$ Acadêmica de Medicina. Universidade Federal do Amapá (UNIFAP).

${ }^{5}$ Acadêmico de Medicina. Universidade Federal do Amapá (UNIFAP).

${ }^{6}$ Biólogo, Doutor em Teoria e Pesquisa do Comportamento, Professor e pesquisador do Curso de Licenciatura em Química do Instituto de Ensino Básico, Técnico e Tecnológico do Amapá (IFAP).

${ }^{7}$ Biólogo, Doutor em Doenças Tropicais, Professor e pesquisador do Curso de Educação Física, Universidade Federal do Pará (UFPA).

${ }^{8}$ Teóloga, Doutora em Psicanálise, pesquisadora do Centro de Pesquisa e Estudos Avançados (CEPA).

${ }^{9}$ Médica, Mestra em Ensino e Ciências da Saúde, Professora e pesquisadora do Curso de Medicina do Campus Macapá, Universidade Federal do Amapá (UNIFAP).

${ }^{10}$ Biomédica, Doutora em Doenças Tropicais, Professora e pesquisadora do Curso de Medicina do Campus Macapá, Universidade Federal do Amapá (UNIFAP).
}

RC: 82162

Disponível em: https://www.nucleodoconhecimento.com.br/saude/doenca-dekawasaki 
estágio febril agudo, em que a congestão conjuntival, mucosite oral, eritema, descamação, erupção cutânea polimórfica e linfadenopatia laterocervical, aparecem como principais sintomas; o estágio subagudo, o qual ocorre no final da febre, e leva ao aparecimento da descamação da pele nos membros, artrite, artralgia e trombocitose e por fim o estágio de convalescença que surge quando os sintomas estão quase dissipando-se e continua até a sua normalização. O tratamento mais usado ocorre a partir da administração da imunoglobulina intravenosa, o qual para melhor prognostico da patologia deve ser iniciado de modo precoce.

Palavras-chave: Síndrome de Linfonodos Mucocutâneos, Vasculite, Arterite, Febre, Kawasaki.

\section{INTRODUÇÃO}

O Doença de Kawasaki (DK) é uma vasculite sistêmica que atinge vasos de pequeno e médio calibre e afeta principalmente crianças menores de 5 anos, sendo uma das razões de enfermidade cardíaca durante a infância (HUANG et al., 2015; MAGALHÃES, 2008). A etiologia da DK, ou seja, os agentes causais dessa enfermidade, não são conhecidos. Porém, alguns aspectos clínicos e epidemiológicos propõem possíveis motivos infecciosos (FERRONATO et al., 2010).

A DK é a segunda vasculite mais comum em idade pediátrica, acometendo principalmente crianças com idade inferior a meia década de vida (90\%). É pouco frequente em crianças menores de 6 meses e maiores de 8 anos, as quais, entretanto, estão mais propensas ao desenvolvimento de aneurismas coronarianos. Numa escala global, há variação de ocorrência, sendo o Japão é país mais afetado, com uma incidência anual de 110 a 150 casos por cada 100.000 crianças com menos de 5 anos. Considerando o cálculo das taxas de incidência em cada 100.000 crianças menores de 5 anos, nos Estados Unidos da América (EUA) a DK é causa mais comum de cardiopatia adquirida na infância, variando de 9,1 a 32,5 casos, ocorrendo com frequência maior naqueles descendentes de asiáticos e das ilhas do

RC: 82162

Disponível em: https://www.nucleodoconhecimento.com.br/saude/doenca-dekawasaki 
pacifico $(32,5)$, intermediaria nos afro-americanos $(16,9)$ e hispânicos $(11,1)$ e pouco frequente em caucasianos $(9,1)$ (ALMEIDA et al., 2010; CASTRO; URBANO; COSTA, 2009; RODRIGUES et al, 2017).

A DK possui mais prevalência na população asiática, com ênfase na japonesa, afetando principalmente crianças. Há o relato de uma incidência anual no Japão e na Coréia de até 100 casos por 100.000 habitantes, já na raça caucasiana a ocorrência é entre 6 a 10 casos por 100.000 habitantes com idade inferior a meia década. Na América Latina, estima-se que ocorram 3 casos por 100.000 habitantes, assim evidenciando uma menor frequência dessa patologia em populações não asiáticas e que não são descentes de asiáticos (SCARDINA et al., 2007). Em relação a taxa de mortalidade associada à $\mathrm{DK}$, mostra-se muito baixa, pois é menor que $0,1 \%$ (BARCA et al., 2019).

A incidência da DK, varia geograficamente no mundo, sendo mais prevalente em descendentes de japoneses, sugerindo uma predisposição genética da doença, além de possíveis agentes causais que podem estar ligados a localização geográfica, como por exemplo, bactérias (CASTRO; URBANO; COSTA, 2009; RODRIGUES et al, 2017).

A variação sazonal na incidência da DK é bem reconhecida, mas taxas mudam entre os países. No Reino Unido, Austrália e EUA, há maior quantitativo de casos no inverno e na primavera. Na China e Coreia, na primavera e verão. Nos EUA e no Reino Unido, a elevação das taxas está mais correlacionada com a variação dos períodos chuvosos que com a variação da temperatura. No Brasil, um estudo realizado com 70 pacientes com DK demonstrou maior registro da doença coincidindo com períodos de maior incidência das doenças infecciosas de maio a junho (início da seca) e novembro e dezembro (início das chuvas) (MAGALHÃES; ALVES, 2017).

Uma pessoa com DK desenvolve características sintomatológicas que levam a apresentação de um quadro clínico, que consiste ao conjunto de sinais e sintomas

RC: 82162

Disponível em: https://www.nucleodoconhecimento.com.br/saude/doenca-dekawasaki 
manifestados pelo paciente (KAYIRAN; DINDAR; GURAKAN, 2010). Dessa maneira, o quadro clínico da DK é caracterizado por linfadenopatia cervical, febre, tonsilite, inchaço dos membros, erupção cutânea, coceira e descamação (ATIK, 2007; SCARDINA et al., 2007). Além disso, a DK pode causar inflamação generalizada, afetando alguns órgãos causando cardiomiopatia inflamatória, meningite estéril, hepatite, adenolinfite, pericardite e angite (CASTRO; URBANO; COSTA, 2009).

Castro, Urbano e Costa (2009) apontam uma relação entre a vasculite causada pela DK e o acometimento de alguns órgãos, que consistem em agrupamento de tecidos responsáveis pela manutenção do organismo.

A DK foi relatada pela primeira vez em 1967, pelo médico Japonês Tomisaku Kawasaki, que a definiu como "síndrome dos linfonodos mucocutâneos". Nesse período, foram descritos 50 casos acompanhados nos anos de 1961 a 1967. No Japão, a ocorrência é mais alta, sendo que a distribuição global tem sua prevalência variável (ALMEIDA et al., 2010; SCARDINA et al., 2007; MAGALHÃES; ALVES, 2017).

No cenário atual, alguns dados epidemiológicos acerca da DK já foram estabelecidos, permitindo uma análise mais apurada dos fatores que intervêm na difusão e propagação de enfermidades. Muitos estudos foram realizados com a finalidade de entender a fisiopatologia da doença, que consiste em conjunto de alterações anormais provocadas no organismo (CASTRO; URBANO; COSTA, 2009).

Em um estudo constataram-se evidências da DK e o avanço de outras comorbidades, que se refere ao fato de duas ou mais doenças estarem ao mesmo tempo em um indivíduo, logo, as complicações da DK seriam a evolução desfavorável dessa associação (SCARDINA et al., 2007).

RC: 82162

Disponível em: https://www.nucleodoconhecimento.com.br/saude/doenca-dekawasaki 
Para melhorar a assistência e a qualidade de vida do portador da DK foram desenvolvidos tratamentos, que consistem em formas de cuidar de um paciente (CASTRO; URBANO; COSTA, 2009).

\section{OBJETIVOS}

Detalhar os possíveis agentes causais, a fisiopatologia, os principais órgãos e estruturas anatômicas acometidas pela Doença de Kawasaki (DK).

Verificar as principais características do quadro clínico de um indivíduo para o diagnóstico, as principais complicações associadas, e os tratamentos disponíveis para os portadores de DK.

\section{MÉTODO}

Trata-se de uma pesquisa bibliográfica realizada nas bases de dados, Scielo, Biblioteca Digital Brasileira de Teses e Dissertações, LILACS e PubMed, utilizando palavras-chave ou suas associações: Kawasaki-doença de Kawasaki.

Os parâmetros de inclusão utilizados na elaboração das buscas foram a disponibilidade integral online, a abordagem direta sobre a Doença de Kawasaki (DK) ou sobre algum aspecto pertinente a esta enfermidade. $\mathrm{Na}$ base de dados Scielo houve filtros de texto das produções redigido na língua inglesa e portuguesa, nas demais bases de dados esse critério não foi utilizado. Os parâmetros de exclusão aplicados foram trabalhos duplicados e realizados antes do ano 2000.

Efetuou-se uma análise nas bases de dados mencionadas para listar os artigos relacionados com a DK existentes na literatura. A partir de uma leitura prévia dos títulos e resumos das produções científicas encontradas, descartou-se estudos que não correspondiam ao que era esperado para constituir esta revisão. Realizou-se a leitura dos textos completos que passaram pelas etapas anteriores, selecionando para esta revisão aquelas que abordavam aspectos relevantes da DK.

RC: 82162

Disponível em: https://www.nucleodoconhecimento.com.br/saude/doenca-dekawasaki 


\section{RESULTADOS}

\section{POSSÍVEIS AGENTES CAUSAIS DA DK}

A causa da doença de Kawasaki ainda é desconhecida. Contudo, suas características clínicas e epidemiológicas alimentam a hipótese de um agente infeccioso ser a causa desencadeante, que produz mudanças nas células, tecidos e órgãos dos indivíduos com predisposição genética. Essa hipótese é a mais provável, mas ainda não possui comprovação (CASTRO; URBANO; COSTA, 2009).

Uma das teorias é a do coronavírus NL-63, detectado por meio de uma Reação em Cadeia Polimerase (PCR) em fluidos das vias respiratórias de 11 pacientes com DK e em apenas 1 dos 22 pacientes de controle. Contudo, outros 5 estudos posteriores não encontraram o coronavírus em amostras de tecido respiratório ou nasofaríneo de doentes, inviabilizando a possibilidade desse vírus ser a causa desencadeante (CASTRO; URBANO; COSTA, 2009).

Outra teoria é a da estimulação imunológica por superantígenos bacterianos como as toxinas estafilocócicas e estreptocócicas. Uma terceira teoria é a imunológica, que propõe que a DK seja causada por uma resposta imunológica aberrante em indivíduos geneticamente predispostos (MAGALHÃES; ALVES, 2017).

\section{FISIOPATOLOGIA DA DK}

As alterações encontradas na DK, especialmente as histológicas, caracterizam um quadro de angiite sistêmica generalizada, atingindo majoritariamente vasos de calibre mediano, especialmente as artérias coronárias. Em vários órgãos podem-se observar alterações infamatórias, como no miocárdio, no pericárdio, nos vasos sanguíneos, nas meninges, no pulmão, nos gânglios linfaticos e no fígado (CASTRO; URBANO; COSTA, 2009).

RC: 82162

Disponível em: https://www.nucleodoconhecimento.com.br/saude/doenca-dekawasaki 


\section{PRINCIPAIS ÓRGÃOS E ESTRUTURAS ANATÔMICAS ACOMETIDAS PELA DK}

A DK afeta órgãos e a artérias, principalmente vasos de calibre mediano de diversos sistemas do corpo humano, como o cardiovascular, o pulmonar, o gastrointestinal (intestino e vesícula biliar são os principais órgãos afetados) e o sistema nervoso central (SNC). Contudo, deve-se destacar a implicação que tal doença tem no coração, com a formação de aneurismas coronarianos (CASTRO; URBANO; COSTA, 2009).

Outras artérias também podem ser afetadas, como: aneurisma de aorta, com maior número de casos relatados comprometendo a aorta abdominal; aneurisma da artéria axilar; aneurisma de artéria braquiocefálica; aneurismas de artérias ilíacas, femorais; aneurisma de artérias renais e obstrução da artéria ocular (ALVES et al., 2011).

\section{PRINCIPAIS CARACTERÍSTICAS DO QUADRO CLÍNICO DE UM INDIVÍDUO PARA O DIAGNÓSTICO DA DK}

A febre, que marca a fase aguda da doença, geralmente é elevada (acima de $39^{\circ} \mathrm{C}$ ) e em picos, diminuindo temporariamente de intensidade durando, aproximadamente, de sete à quatorze dias, podendo chegar a três e/ou quatro semanas se não houver o tratamento adequado. O dia no qual a febre começa é considerado o primeiro dia da doença. Contudo, alguns pacientes apresentam outras manifestações clássicas antes da febre, como: conjuntivite não purulenta; linfonodomegalia cervical; eritemas e/ ou edemas nas mãos e pés; exantema escalartiniforme, morbiliforme ou polimórfico; língua framboesiforme, eritema e edema de orofaringe, fissuras e eritema labial (CASTRO; URBANO; COSTA, 2009).

As alterações nas extremidades (mãos e pés) com eritemas e/ou edema, surgem também na fase aguda, sendo que o edema é muito doloroso e está associado ao eritema palmoplantar com vasculite nas pontas dos dedos que após um período de

RC: 82162

Disponível em: https://www.nucleodoconhecimento.com.br/saude/doenca-dekawasaki 
uma a duas semanas, já na fase subaguda, começa a descamar, iniciando pela região periungueal em dedo de luva (MAGALHÃES; ALVES, 2017).

A conjuntivite bilateral não exsudativa afeta especialmente a conjuntiva bulbar quando comparada às conjuntivas palpebral e tarsal e é indolor. Às vezes, é acompanhada por iridociclite, uma inflamação da parte anterior do olho, com de resolução rápida e pouco associada a sensibilidade a luz (CASTRO; URBANO; COSTA, 2009).

O rash polimórfico é um conjunto de erupções cutâneas que ocorrem nos primeiros dias da doença, afetando principalmente o tronco e as extremidades, sem bolhas ou vesículas aparentes. Possuem apresentação variável (rash urticariforme, morbiliforme, maculopapular) ou difusa, lembrando a escarlatina (ALMEIDA et al., 2010).

Alterações nos lábios e cavidade oral 9 a cada 10 casos na fase aguda com intensa hiperemia labial e orofaringeana, fissuras, mucosa seca e sangramento dos lábios. As papilas da língua podem se tornar proeminentes e ulcerações orais com exsudato em orofaringe podem ser, às vezes, observados. Quanto à linfadenomegalia cervical, outro critério diagnóstico, o paciente deve apresentar pelo menos um nódulo linfático com um diâmetro maior ou igual a $1,5 \mathrm{~cm}$, comumente unilateral, doloroso e firme, no triangulo cervical anterior (ALMEIDA et al., 2010; MAGALHÃES; ALVES, 2017).

\section{AS PRINCIPAIS COMPLICAÇÕES ASSOCIADAS A DK}

Em pacientes com DK, identificam-se em momentos diferentes da evolução da doença três tipos de vasculopatias: arterite necrosante, arterite subaguda/crônica e vasculite por proliferação miofibroblástica luminal. $\mathrm{Na}$ fase aguda da doença destaca-se a arterite necrosante, que tem seu processo patológico completo nas duas primeiras semanas após o começo do quadro febril, especialmente nas artérias coronárias, podendo determinar a formação de aneurismas gigantes suscetíveis ao

RC: 82162

Disponível em: https://www.nucleodoconhecimento.com.br/saude/doenca-dekawasaki 
desenvolvimento de tromboses e roturas. $\mathrm{Na}$ fase subaguda, verifica-se que o processo de vasculite subaguda começa 2 semanas após o aparecimento da febre, podendo afetar todos os vasos sanguíneos, principalmente o segmento médio das artérias musculares de médio porte, como as artérias coronárias. Na fase crônica da doença, ocorre a mioproliferação fibroblástica luminal, associado com a vasculite subaguda crônica (MAGALHÃES; ALVES, 2017).

A complicação mais grave da doença é a vasculite coronariana, com alterações nas artérias coronárias, que afeta $15-20 \%$ dos pacientes que não recebem tratamento. Essas alterações incluem aneurismas, ectasias e estenoses das artérias coronárias, responsável por $2 \%$ de mortalidade (ALMEIDA et al., 2010).

No sistema gastrointestinal, tem-se vômitos, diarreia, dor abdominal e íleo paralítico. No início da febre, as manifestações mais frequentes são vômitos e diarreia e as menos comuns são a icterícia, hepatomegalia dolorosa, pancreatite e vesícula hidrópica. No aparelho respiratório, as manifestações mais frequentes são tosse, pneumonite e alterações radiológicas. Raramente ocorre rinorreia (MAGALHÃES; ALVES, 2017).

No SNC a doença pode se manifestar com extrema irritabilidade na fase aguda, além de meningite asséptica, ataxia, paralisia facial e perda auditiva neurossensorial. Destaca-se também a presença de ganglionite e neurite em nervos cranianos e periféricos, endarterite, periarterite, coriomeningite e leptomeningite, além de atrofia, degeneração com perda de neurônios, gliose marginal e subpendimal e formação de nódulos gliais ao redor das degenerações de neurônios (MAGALHÃES; ALVES, 2017).

Mudanças de comportamento, como deficiência de atenção, deficiência no aprendizado, alterações emocionais (labilidade emocional, medo e terror noturno) e problemas de internalização (comportamento ansioso, depressivo e agressivo) têm sido descritas na literatura (ALVES et al., 2011).

RC: 82162

Disponível em: https://www.nucleodoconhecimento.com.br/saude/doenca-dekawasaki 


\section{TRATAMENTOS DISPONÍVEIS PARA INDIVÍDUOS ACOMETIDOS PELA DK}

A terapia para DK possui duas finalidades diferentes dependendo da fase na qual se encontra. $\mathrm{Na}$ fase aguda, tem por objetivo a redução da resposta inflamatória na parede da artéria coronária e a prevenção da vasculite e suas consequências (trombose e aneurismas). Já nas fases subaguda e crônica, visa-se prevenir a isquemia miocárdica e o infarto (CASTRO; URBANO; COSTA, 2009).

A Imunoglobulina Endovenosa (IGEV) é o principal medicamento utilizado na DK e seu mecanismo de ação permanece desconhecido. É utilizada na fase aguda, de preferência nos primeiros 7 a 10 dias do início do quadro (MAGALHÃES; ALVES, 2017).

O tratamento consiste na administração de imunoglobulina em dose única de $2 \mathrm{~g} / \mathrm{kg}$ durante um período variável de 10 a 12 horas em conjunto com a administração de ácido acetilsalicílico (AAS) 80 a $100 \mathrm{mg} / \mathrm{kg} / \mathrm{dia}$, via oral, 6/6 horas. O AAS em altas doses apresenta efeito anti-inflamatório e, em baixas doses, atua como inibidor da agregação plaquetária, de modo que o tempo de uso do AAS em altas doses deve permanecer até que a criança esteja afebril. Em seguida, é feita a diminuição da dose para 3 a $5 \mathrm{mg} / \mathrm{kg} / \mathrm{dia}$ e mantida nessa dose enquanto o paciente apresentar plaquetose e/ou alterações coronarianas (MAGALHÃES; ALVES, 2017; RODRIGUES et al., 2017).

Entre 1 e 2 a cada 10 dos pacientes com DK não respondem à primeira dose de IGEV, ou com a permanência do quadro febril ou com o reaparecimento dele um dia e meio após a primeira infusão. Esses pacientes são considerados refratários ao tratamento e são os que possuem mais risco de alterações coronarianas. Nesses casos, é recomendada a administração da segunda dose de IGEV de $2 \mathrm{~g} / \mathrm{kg}$ em dose única. Se a febre persistir por 36 horas, recomenda-se o uso de pulsoterapia

RC: 82162

Disponível em: https://www.nucleodoconhecimento.com.br/saude/doenca-dekawasaki 
com metilprednisolona na dose de $30 \mathrm{mg} / \mathrm{kg} / \mathrm{dia}$ (dose máxima $1 \mathrm{~g} / \mathrm{dia}$ ), infundida em 1 hora, 1 vez/dia, durante 3 dias (MAGALHÃES; ALVES, 2017).

No tratamento da DK nas fases subaguda e crônica, é usada a aspirina em doses baixas (3-5 $\mathrm{mg} / \mathrm{kg} / \mathrm{dia})$ em crianças com pequenos e médios aneurismas. Nessas fases, o tratamento visa prevenir a trombose (ativação plaquetária) e estenose do vaso. Outros agentes antiplaquetários também são utilizados (clopidogrel, ticlopidina, dipiridamol) e, associados a aspirina, estão se apresentando como mais concretos no bloqueio da agregação plaquetária (CASTRO; URBANO; COSTA, 2009).

\section{DISCUSSÃO}

\section{CORRELAÇÃO ENTRE OS POSSÍVEIS AGENTES CAUSAIS E O DESENVOLVIMENTO DA DK}

Até o momento, a origem da KD não foi identificada, porém existem alguns agentes, os quais, acredita-se estarem relacionados ao desenvolvimento da patologia. Entre esses estão o Staphylococcus aureus, estreptococos, vírus influenza, morbilivírus, paramixovírus, bunyavírus. O adenovírus e um novo coronavírus humano denominado coronavírus de New Haven (Nco-NH), também podem estar associados a DK, pois já foram identificados nas secreções do trato respiratório de pacientes com a doença. Tais vírus e bactérias, poderiam agir no desenvolvimento da DK, de modo que acarretariam dados causados pela doença, como por exemplo os aneurismas na aorta (BARCA et al., 2019; CASTRO; URBANO; COSTA, 2009).

Existe uma hipótese que associa a existência de superantígenos bacterianos com o desenvolvimento da DK. Os estudos que analisam essa sugestão supõem que o superantígeno consegue se ligar à célula apresentadora de antígenos, através do complexo de histocompatibilidade maior de classe II (MHC classe II) e do receptor de linfócito $T$ em locais de ligação diferentes dos de antígenos comuns. Isso

RC: 82162

Disponível em: https://www.nucleodoconhecimento.com.br/saude/doenca-dekawasaki 
promoveria uma resposta imunológica com formação e liberação de citocinas próinflamatórias em concentrações excessivas, contribuindo para a evolução de um processo inflamatório característico da DK (CASTRO; URBANO; COSTA, 2009).

Alguns indícios, levam a acreditar-se que ocorra uma resposta oligoclonal IgA na DK aguda. Um estudo conduzido por Castro, Urbano e Costa (2009) realizou a análise da cadeia pesada alfa de imunoglobulinas coletadas de uma grande quantidade de leucócitos acumulados em um local de resposta inflamatória da parede arterial de pacientes com DK, a qual mostrou que anticorpos específicos Imunoglobulinas A ( $\lg A)$ foram detectados na amostra. Isso evidencia a existência de uma resposta imune relacionada com a DK (CASTRO; URBANO; COSTA, 2009).

A hipótese de que a DK possua predisposição genética é potencializada pela alta incidência entre asiáticos e seus pósteros. Um estudo evidenciou 67 genes relacionados ao desenvolvimento da patologia, os quais acarretavam acometimentos no endotélio, no metabolismo lipídico, na ativação de mecanismos imunológicos e recrutamento plaquetário, apoiando a ideia de que há uma relação genética para o desenvolvimento da DK (CASTRO; URBANO; COSTA, 2009; SOTELO; GONZÁLEZ, 2007).

\section{FISIOPATOLOGIA DA DK}

A vasculite começa pela ocorrência de inchaço e inflamação, que pode ocorrer por um período variável. Os neutrófilos estão presentes inicialmente, e logo em seguida há o predomínio de linfócitos T citotóxicos CD8+ e imunoglobulina IgA (CASTRO; URBANO; COSTA, 2009).

Nas artérias coronárias há alterações inflamatórias com presença de edema e necrose de células musculares. Com essa perda da integridade estrutural tem-se a formação dos aneurismas. Ademais, os fibroblastos se proliferam, e em seguida realizam a remodelação, levando a possível presença de estenoses, calcificações e a trombose (CASTRO; URBANO; COSTA, 2009; SOTELO; GONZÁLEZ, 2007).

RC: 82162

Disponível em: https://www.nucleodoconhecimento.com.br/saude/doenca-dekawasaki 
É importante observar que o fator inflamatório 1 encontrado em aloenxertos, é acentuadamente aumentado em tecidos arteriais estenóticos de KD. Esse fator inflamatório 1 do aloenxerto liga a resposta do interferon tipo I até a ativação de macrófagos e linfócitos $T$ específicos, o que supõe a provável importância da interferência dessas células na arterite por KD (ROWLEY et al., 2017).

\section{COMO OS PRINCIPAIS ÓRGÃOS E ESTRUTURAS ANATÔMICAS SÃO ACOMETIDAS PELA DK}

A DK atinge órgãos e artérias, principalmente vasos de médio porte, como os do coração, especificamente as artérias coronarianas, com a formação de aneurismas. A doença também pode afetar o sistema respiratório (pulmão), através da vasculite, o sistema gastrointestinal, principalmente o intestino e a vesícula biliar, e o sistema nervoso (CASTRO; URBANO; COSTA, 2009).

O sistema linfático pode ser acometido com a DK, pois um dos sintomas da DK é o inchaço dos linfonodos cervicais. Já o sistema cutâneo é danificado, mediante eritema cutâneo, seguido de edemas. Nos olhos pode ocorrer a hiperemia conjuntural não supurativas e as mucosas da cavidade oral podem ser atingidas pela mucosite oral e lesões nos lábios (SOTELO; GONZÁLEZ, 2007).

\section{AS PRINCIPAIS CARACTERÍSTICAS DO QUADRO CLÍNICO DE UM INDIVÍDUO COM DK E COMO O AFETAM}

O curso clínico da DK pode ser dividido em três estágios clínicos: aguda, subaguda e convalescença. O estágio febril agudo, geralmente, dura de 7 a 14 dias, caracterizado por congestão conjuntival, mucosite oral, eritema, descamação e erupção cutânea polimórfica e linfadenopatia. O estágio subagudo é o período entre o final da febre e $\circ 2^{\circ}$ dia da doença. Nessa fase, os pacientes apresentam descamação da pele nos membros, artrite, artralgia e trombocitose. O estágio de convalescença se inicia quando os sintomas clínicos começam a desaparecer e

RC: 82162

Disponível em: https://www.nucleodoconhecimento.com.br/saude/doenca-dekawasaki 
continua até o estabelecimento normal da VHS (velocidade de hemossedimentação das hemácias), que geralmente é observada após 6 a 8 semanas do começo dos sintomas. Tais estágios afetam a vida do paciente, uma vez que o impedem de realizar suas atividades cotidianas, o que se deve principalmente as lesões nas peles e sintomatologia (ALMEIDA, 2017; SCARDINA et al., 2007).

O quadro sugestivo da patologia, é caracterizado por febre, aumento dos linfonodos cervicais e amigdalite, seguido de eritema cutâneo generalizado, prurido e edema dos membros e após alguns dias a descamação. Os exames laboratoriais mostram fase inflamatória ativa com taxa de sedimentação elevada, proteína $C$ reativa, leucocitose e aumento do número de plaquetas, o que leva a uma letargia do indivíduo acometido, já que a inflamação pode ocasionar fortes dores (ALMEIDA, 2018; ATIK; FORONDA; BUSTAMANTE, 2003; FERRONATO et al., 2010; ROSSI et al., 2015).

Também podem surgir a hiperemia conjuntural não supurativa; exantema macularpapular; lesões nos lábios e cavidade oral; alterações na pele das extremidades, além de sopro precordial, dificuldade respiratória, dor abdominal, disúria, hepatomegalia, artralgia, enrijecimento do pescoço e convulsões. Esses sintomas, impedem o paciente de ver e se locomover normalmente, já que os olhos são prejudicados e as dores causam dificuldade, para a realização de movimentos (CASTRO; URBANO; COSTA, 2009; SOTELO; GONZÁLEZ, 2007).

A DK atinge vários pacientes com a vasculite em vários órgãos, como já foi dito anteriormente, o pulmão, intestino, vesícula biliar, sistema nervoso central, são exemplo, o que leva ao aparecimento de sintomas como, fadiga, perda de peso e dores nas articulações e músculos, mas os danos cardíacos são os mais significativos, com a formação de aneurismas coronarianos, os quais levam a angina (CASTRO; URBANO; COSTA, 2009; PRINTZ, 2011).

Outro sintoma é a irritação, a qual aparece nas crianças com a doença, sendo que as queixas gastrointestinais, incluindo diarreia, vômito e dor abdominal, ocorrem em

RC: 82162

Disponível em: https://www.nucleodoconhecimento.com.br/saude/doenca-dekawasaki 
cerca de um terço dos pacientes, o que explica o fato de crianças com DK serem mais irritadas que as demais (ALMEIDA, 2018; KAYIRAN; DINDAR; GURAKAN, 2010).

O abscesso e edema retrofaríngeo, geralmente está associada a uma condição fatal, se não for tratada adequadamente. Os otorrinolaringologistas, podem tratá-la com drenagem cirúrgica do abscesso, impedindo o bloqueio das vias aéreas (KIM; KWON, 2016; XIE et al., 2018).

A mucosite oral é representada por eritema difuso da membrana mucosa, vermelhidão nos lábios e língua e hipertrofia das papilas linguais com subsequente desenvolvimento da língua morango, e geralmente ocorre no estágio agudo da doença e no de convalescença., como consequência do tratamento farmacológico, e impede que o paciente se alimente adequadamente devido as lesões, afetando sua nutrição adequada (SCARDINA et al., 2007).

\section{O DIAGNÓSTICO DA DK}

A DK representa um desafio para ser diagnosticada precocemente, pois é uma afecção reumatológica incomum que requer intervenção específica, a fim de serem evitadas sequelas graves ou fatais (ALMEIDA et al., 2010).

A clínica da doença não é clara, sendo comum o diagnóstico inicial de outras doenças, como escarlatina, exantema viral ou quadros alérgicos, devido aos sintomas iniciais da doença. Mesmo com o preenchimento completo dos critérios, é frequente a demora no diagnóstico correto, o que leva a um atraso no início do tratamento adequado, favorecendo o aparecimento das complicações, o que pode agravar rapidamente o quadro clinico do paciente. Além disso, existem as formas incompletas ou atípicas, que dificultam ainda mais o diagnóstico. O diagnóstico precoce da doença é importante, pois o tratamento na fase aguda reduz o processo inflamatório nas artérias coronarianas e previne a trombose, reduzindo as chances de mortalidade (FERRONATO et al., 2010).

RC: 82162

Disponível em: https://www.nucleodoconhecimento.com.br/saude/doenca-dekawasaki 
O diagnóstico clínico oportuno é fundamental para estabelecer esse tratamento precoce e evitar lesões nas coronárias. Esse tipo de lesão pode causar isquemia ou infarto do miocárdio, o que é extremamente grave (KAYIRAN; DINDAR; GURAKAN, 2010; SOTELO; GONZÁLEZ, 2007).

Os critérios diagnósticos da doença de DK clássica são a febre com cinco dias ou mais, além de no mínimo quatro outros critérios, os quais são: eritema palmo-plantar com ou sem edema doloroso ou descamação periungueal; Exantema polimorfo; hiperemia conjuntival bulbar dos dois lados, não exsudativa; Alterações dos lábios e da mucosa oral; Linfadenopatia cervical - diâmetro superior a $1,5 \mathrm{~cm}$, dura e indolor à palpação. $\mathrm{O}$ diagnóstico de $\mathrm{DK}$ incompleta pode ser estabelecido na presença de três ou mais dos critérios a seguir descritos: Albumina $\leq 3 \mathrm{~g} / \mathrm{dL}$; Anemia; Elevação da alanina aminotransferase; Plaquetas após os sete dias $\geq 450.000 / \mathrm{mm}^{3}$; Leucócitos $\geq$ 15.000/ $\mathrm{mm}^{3}$; Urina $\geq 10$ leucócitos (CASTRO; URBANO; COSTA, 2009; RODRIGUES et al., 2017; YAP; LIN; WANGUI, 2012).

As principais sequelas da doença estão relacionadas ao sistema cardíaco, portanto, a imagem cardíaca por ecocardiografia é uma parte relevante da avaliação de pacientes com suspeita de DK. Para casos não complicados, a ecocardiografia é recomendada no momento do diagnóstico, 6 a 8 semanas, após o início da doença (ATIK et al., 2017; KAYIRAN; DINDAR; GURAKAN, 2010)

As alterações laboratoriais mais observadas são hemograma com leucocitose e neutrofilia, além de aumento dos valores de exames de fase aguda, como velocidade de hemossedimentação e proteína C-reativa. A doença, muitas vezes, só é diagnosticada após se constatar o acometimento das coronárias (FERRONATO et al., 2010).

Um estudo realizado por Kentsis et al. (2013) constatou que os marcadores filamina $\mathrm{C}$ e meprina $\mathrm{A}$ foram detectados tanto no soro quanto na urina dos dois grupos independentes de paciente com DK participantes. O mesmo estudo constata o uso

RC: 82162

Disponível em: https://www.nucleodoconhecimento.com.br/saude/doenca-dekawasaki 
desses marcadores para a realização do diagnóstico de DK como sendo mais eficiente que o uso dos marcadores atualmente utilizados (KENTSIS et al., 2013).

\section{EXAMES DE IMAGEM E COMPLEMENTARES}

O ecocardiograma é um dos principais exames usados para o diagnóstico da DK, já que ele não é invasivo, possui uma alta sensibilidade e especificidade para analisar e detectar anormalidades nas artérias coronárias, avaliar o miocárdio e verificar a presença de pericardite. Nesse exame pode aparecer alguns achados que indiquem a arterite coronariana, a qual precede a formação dos aneurismas, como o brilho perivascular, ectasia ou estreitamento das artérias coronárias. $\mathrm{Na}$ análise das artérias coronarianas deve-se avaliar o diâmetro interno do vaso; o número, localização e o tipo (se sacular ou fusiforme) de aneurismas; e a presença ou não de trombo intraluminal e de estenose. $\mathrm{Na}$ fase aguda da doença alguns achados frequentes nos ecocardiogramas são: redução da contratilidade do ventrículo esquerdo, regurgitação da valva mitral e efusão pericárdica (CASTRO; URBANO; COSTA, 2009; MAGALHÃES; ALVES, 2017; RODRIGUES et al., 2017).

Outros exames que podem ser realizados, baseados na disponibilidade, gravidade, vantagens e indicações que variam de acordo com o caso. Por exemplo, pode ser citado a ressonância nuclear magnética (RNM), angioressonância, radiografia do tórax, tomografia computadorizada de alta resolução, angiografia (CASTRO; URBANO; COSTA, 2009).

A angiotomografia, um exame invasivo que possui riscos, e a angiorressonância normalmente são realizados naqueles pacientes que apresentaram anormalidade no eletrocardiograma, ecocardiográficas ou sintomas de isquemia do miocárdio (CASTRO; URBANO; COSTA, 2009; MAGALHÃES; ALVES, 2017).

Ultimamente, tomografia computadorizada de alta resolução tem sido mais indicada, principalmente quando comparada a RNM, uma vez que sua execução é mais veloz

RC: 82162

Disponível em: https://www.nucleodoconhecimento.com.br/saude/doenca-dekawasaki 
e de mais fácil interpretação, enquanto a RNM requer um maior tempo anestésicos das crianças para coleta (CASTRO; URBANO; COSTA, 2009).

A radiografia de tórax, que geralmente não apresenta alterações, em aproximadamente $15 \%$ dos casos são descobertas anomalias, como: padrão de infiltrado reticulogranular ou peribrônquio, acumulo demasiado de liquido no espaço entre as pleuras visceral e parietal ou colapso do pulmão. Elas aparecem após o $10^{\circ}$ dia da doença e são possíveis de verificar nas radiografias de 10 a 50 dias após o começo do quadro (CASTRO; URBANO; COSTA, 2009).

Em exames laboratoriais, os achados não são específicos da DK, mas sim, um indicativo de elevado processo inflamatório sendo possível achar, no começo da fase aguda, aumento nas taxas de Velocidade de Hemossedimentação (VHS), proteína $C$ reativa $(P C R)$ e a alfaglicoproteína ácida. No exame de sangue é possível verificar uma quantidade anormalmente elevada de neutrófilos, chamada leucocitose com neutrofilia, podendo ser acompanhada pelo aumento de bastões ou eosinofilia. Ademais, a quantidade de plaquetas geralmente costuma está normal na fase aguda, contudo, é possível que em alguns casos haja plaquetopenia, que está associada ao desenvolvimento de doença coronariana grave e infarto do miocárdio (MAGALHÃES; ALVES, 2017).

\section{ANÁLISE DAS PRINCIPAIS COMPLICAÇÕES ASSOCIADAS A DK}

A complicação mais grave da doença é a vasculite coronariana, que afeta 15-20\% dos pacientes não tratados, podendo levar a aneurismas, ectasias e estenoses das artérias coronárias, responsáveis por $2 \%$ de mortalidade. Outras complicações da DK têm sido descritas como aneurismas em outras artérias como, a aorta; a aorta abdominal; artéria axilar; artéria braquiocefálica; artérias ilíacas, femorais e artérias renais, o que indica como DK pode afetar de modo vasto o corpo humano, e assim ser extremamente perigosa (ALVES, et al., 2011; CHBEIR et al., 2018; MUTLUER; ÇELIKER, 2019; PRINTZ, 2011; XIE et al., 2018).

RC: 82162

Disponível em: https://www.nucleodoconhecimento.com.br/saude/doenca-dekawasaki 
Alguns pacientes com DK estão suscetíveis a dilatação coronária progressiva. Tal dilatação da artéria coronária ocorre durante a fase aguda e pode prosseguir para fase subaguda, o que agrava o quadro clinico de diversos pacientes (BRIEDÉ et al., 2015; 2015; LIU et al., 2017).

Complicações gastrointestinais na DK podem ocorrer como obstrução intestinal, edema em cólon, isquemia intestinal, pseudo-obstrução intestinal e abdome agudo, o que afeta o paciente de modo alarmante, pois essas complicações podem levar a quadros de sepse e até mesmo a morte. Além disso, alterações oftalmológicas associadas à DK podem compreender, a uveíte, iridociclite, hemorragia conjuntival, neurite óptica, amaurose e obstrução da artéria ocular, o que ocasiona sequelas irreparáveis por diversas vezes. A DK também se manifesta como vasculite necrosante, assim levando a perda do tecido afetado (ALVES, et al., 2011).

Complicações neurológicas por lesão do sistema nervoso central (SNC) podem ser as seguintes: meningoencefalite, coleção subdural, hipoperfusão cerebral, isquemia, infarto cerebral, convulsões, emiplegia, confusão mental, letargia e até mesmo o coma ou infarto cerebral. Tais complicações, podem se tornar irreversíveis, assim prejudicando para sempre a vida do paciente (ALVES, et al., 2011).

O risco de complicações tardias da DK sugere a necessidade de um acompanhamento em longo prazo, além da infância (GIACCHI et al., 2014).

\section{OS TRATAMENTOS DISPONÍVEIS PARA INDIVÍDUOS ACOMETIDOS PELA DK}

O tratamento mais indicado é a aplicação de IGIV (Imunoglobulina Intravenosa) em dose única de $2 \mathrm{~g} / \mathrm{kg}$ por infusão de 12 horas. De acordo com a evolução do quaro clinico do paciente, a dose de IGIV pode ser repetida ou podem ser adicionados corticóides, principalmente em casos refratários. Outros fármacos são recomendados, como ciclosfosfamida, ciclosporina e ulinastatina. Também, é recomendado um produto baseado em anticorpos monoclonais contra o fator de

RC: 82162

Disponível em: https://www.nucleodoconhecimento.com.br/saude/doenca-dekawasaki 
necrose tumoral alfa, e ainda um anticorpo monoclonal, conhecido como Abciximab, e que pode tratar mais rapidamente aneurismas (ATIK, 2007; FERRONATO et al., 1010; KAYIRAN; DINDAR; GURAKAN, 2010; PHILIP et al., 2017; SOTELO; GONZÁLEZ, 2007).

Aproximadamente 10 a $15 \%$ dos pacientes com DK não demonstram melhora com o tratamento com IGIV, que é o tratamento padrão (MEHNDIRATTA et al., 2014). Em pacientes pediátricos com DK, doses altas de ácido acetilsalicílico (AAS) proporcionam ação anti-inflamatória, enquanto doses baixas apresentam efeito inibitório da agregação plaquetária. Dessa forma, na fase aguda da doença se faz o uso de AAS $80-100 \mathrm{mg} / \mathrm{kg} / \mathrm{dia}$, que é dividido em quatro ingestões ao longo do dia, com o intuito de intensificar o efeito anti-inflamatório da IGIV. Enquanto em alguns hospitais a dose de AAS é reduzida após 2-3 dias na ausência de febre, em outros centros de saúde o tratamento persiste por até 2 semanas. Ademais, crianças que apresentam anormalidades cardíacas possuem prescrição de AAS em altas doses indefinidamente (ATIK, 2007; CASTRO; URBANO; COSTA, 2009; MEHNDIRATTA et al., 2014).

Também são usados medicamentos da classe de imunossupressores como ciclofosfamida, em conjunto com a prednisona ou metilprednisolona, para melhorar alguns sintomas, como por exemplo a febre, porém essas medicações não surtem efeito terapêutico nas anormalidades cardíacas (CASTRO; URBANO; COSTA, 2009; PHILIP et al., 2017).

$\mathrm{Na}$ fase aguda da doença de DK, existe um maior risco cirúrgico, pois, na presença de inflamação, a anastomose com artéria coronária inflamada corre o risco de obstrução. A abordagem cirúrgica deve ser restrita a pacientes com aneurismas gigantes ou processos isquêmicos após a fase aguda (ATIK, 2007; SOTELO; GONZÁLEZ, 2007).

A revascularização cirúrgica de lesões coronárias secundárias à DK é relativamente incomum. De acordo com as diretrizes atuais, a revascularização arterial completa

RC: 82162

Disponível em: https://www.nucleodoconhecimento.com.br/saude/doenca-dekawasaki 
deve ser usada em pacientes jovens com pequenas comorbidades, a fim de obter uma boa permeabilidade do enxerto a longo prazo (BARCA et al., 2019).

Além da cirurgia de revascularização do miocárdio, que tem sido o tratamento de escolha para complicações coronarianas trombóticas da DK, a intervenção coronária percutânea (ICP) com stents regulares ou percutâneos com politetrafluoretileno (PTFE), implante de bobina, revascularização coronária transluminal percutânea (PTCR) com aplicação de agentes trombolíticos na artéria relacionada ao infarto, e a ablação rotatória coronária percutânea (PTCRA), veem sendo usados nos pacientes acometido pela doença (MUTLUER; ÇELIKER, 2019).

Quanto ao manejo anestésico, há pouca informação descrita, porém, a revascularização do miocárdio com anestesia realizado por gases halogenados apresentam menor dano, assim evidenciado melhor recuperação pós-operatória da função do miocárdio em comparação com anestésicos intravenosos. Dessa maneira, favorece a inibição da resposta neuroendócrina ao estresse, e também prepara o paciente para uma extubação precoce no pós-operatório, o que auxilia na prevenção de possíveis complicações decorrentes da intubação (MARTíNEZ; MÉNDEZ, 2013).

\section{CONCLUSÃO}

A ocorrência de DK é variável, estando mais presente na região da Ásia, principalmente em crianças menores de 5 anos. Na América Latina a incidência é menos frequente e a mortalidade dessa patologia é baixa.

O agente etiológico da DK não foi identificado, mas há alguns patógenos, que podem estar relacionados com essa enfermidade. Existem evidencias que essa enfermidade possui uma relação genética, isso se constatou devido ao aumento da incidência entre pessoas asiáticas e entre parentes de doentes acometidos pela DK, além disso, há também alguns genes que estão associados a esta patologia.

RC: 82162

Disponível em: https://www.nucleodoconhecimento.com.br/saude/doenca-dekawasaki 
Há alterações associadas à DK como inflamações sistêmicas, acometendo determinados órgãos ocasionado angiite, meningite estéril, pneumonite, adenofinite e hepatite. A DK atinge, órgãos e a artérias, principalmente vasos de médio calibre, como os do coração, de modo que leva a formação de aneurismas, pode afetar os olhos, as mucosas da cavidade oral, o pulmão, o intestino, vesícula biliar e o sistema nervoso, o sistema linfático, sistema cutâneo e pode ocorrer lesões nos lábios.

O quadro clínico da DK possui três estágios. O estágio febril agudo, é caracterizado por congestão conjuntival, mucosite oral, eritema, descamação, erupção cutânea polimórfica e linfadenopatia laterocervical. O estágio subagudo, ocorre no final da febre, os pacientes apresentam descamação da pele nos membros, artrite, artralgia e trombocitose. O estágio de convalescença surge quando os sintomas estão quase desaparecendo e continua até a sua normalização.

A demora no diagnóstico correto da DK é bastante frequente, podendo levar a um atraso no início do tratamento, podendo ocasionar o aparecimento de complicações, agravando o quadro clinico. O diagnóstico clínico no início é extremamente importante para estabelecer um tratamento precoce e evitar lesões nas artérias coronarianas.

O tratamento da DK é feito baseado na evolução do quadro clínico do paciente. A terapêutica mais utilizada é a aplicação de IGIV, se ocorrer alteração na clínica, a dose de IGIV pode ser repetida ou podem ser adicionados corticóides. Outros medicamentos podem ser indicados, como ciclosfosfamida, ciclosporina e ulinastatina. Recomenda-se também um produto baseado em anticorpos monoclonais o Infliximab, pode haver a utilização de imunossupressores como ciclofosfamida ou ciclosporina e a prednisona ou metilprednisolona. O tratamento cirúrgico é feito principalmente na fase aguda da DK, mas deve ser restrito a enfermos com aneurismas gigantes ou processos isquêmicos após a fase aguda da doença.

RC: 82162

Disponível em: https://www.nucleodoconhecimento.com.br/saude/doenca-dekawasaki 


\section{REFERÊNCIAS}

ALMEIDA, F. C. Avaliação das manifestações clínicas e achados laboratoriais em 301 pacientes com doença de Kawasaki: acompanhamento de dez anos. Tese (Doutorado em Ciências Médicas). Faculdade de Medicina, Universidade de Brasília, Brasília. 2018.

ALMEIDA, M. A. A. L. S. Avaliação da calprotectina e dos anticorpos anticitoplasma de neutrófilos como marcadores de inflamação e autoimunidade nas diferentes fases da doença de Kawasaki. Dissertação (Mestrado em Ciências Farmacêuticas). Faculdade de Ciências da Saúde, Universidade de Brasília, Brasília. 2017.

ALMEIDA, R. G. et al. Perfil da doença de Kawasaki em crianças encaminhadas para dois serviços de reumatologia pediátrica do Rio de Janeiro, Brasil. Revista Brasileira de Reumatologia, v. 50, n. 5, p. 529-538, set./out. 2010.

ALVES, N. R. M. et al. Estudo prospectivo das complicações da Doença de Kawasaki: análise de 115 casos. Revista da Associação Médica Brasileira, v. 57, n. 3, p. 299-305, mar. 2011.

ATIK, E. Doença de Kawasaki: Regressão de Aneurismas Gigantes das Artérias Coronárias com Obstrução Tardia Posterior Kawasaki Disease: Giant Coronary Arteries Aneurysms Regression and Later Stenosis. Arquivos brasileiros de Cardiologia, v. 88, n. 1, p. 22-23, 2007.

ATIK, E.; FORONDA, A.; BUSTAMANTE, L. N. P. Kawasaki Disease. Involution of Giant Coronary Aneurysms After Prolonged Anti-inflammatory Treatment. Arquivos brasileiros de Cardiologia, v. 81, n. 3, p. 265-72, set. 2003. 
ATIK, E. et al. Caso 6/2017 - Extenso Aneurisma Gigante de Artéria Coronária Esquerda por Vasculite de Kawasaki em Homem Assintomático com 48 Anos de Idade. Arquivos brasileiros de Cardiologia, v. 109, n. 5, p. 489-490, nov. 2017.

BARCA, L. V. et al. Ligature of the Left Main Coronary Artery after Surgery in Kawasaki Disease: Case Report. Braz J Cardiovasc Surg, v. 34, n. 1, p. 111-113, jan./fev., 2019.

BRIEDÉ, S. et al. Hamoen M, Oosterveld M JS, Breur JMPJ. Langetermijneffecten van de ziekte van Kawasaki. Ned tijdschr geneeskd, v. 154, n. 2121, p. 1-6, out. 2015.

CASTRO, P. A.; URBANO, L. M. F.; COSTA, I. M. C. Doença de Kawasaki. Anais Brasileiros de Dermatologia, v. 84, n. 4, p. 317-331, mai. 2009.

CHBEIR, D. et al. Kawasaki disease: abnormal initial echocardiogram is associated with resistance to IV Ig and development of coronary artery lesions. Pediatric Rheumatology Onlinw Journal, v. 6, n. 48, p. 1-10, jul. 2018.

FERRONATO, A. E. et al. Doença de Kawasaki: experiência clínica em hospital universitário. Revista Paulista de Pediatria, v. 28, n. 2, p. 148-154, jun. 2010.

GIACCHI, V. et al. Avaliação do espessamento íntimo da artéria coronária em pacientes com diagnóstico prévio de doença de Kawasaki por meio de ecocardiografia transtorácica de alta resolução: nossa experiência. BMC Cardiovasc Disord, v. 14, n. 106, p 1-6, ago. 2014.

HUANG, X. et al. Influenza infection and Kawasaki disease. Revista da Sociedade Brasileira de Medicina Tropical, v. 48, n. 3, p. 243-248, jun. 2015.

KAYIRAN, S. M.; DINDAR, A. N.; GURAKAN, B. An evaluation of children with Kawasaki disease in Istanbul: a retrospective follow-up study. Clinical Science, v. 65, n. 12, p. 1261-1265, dez. 2010.

RC: 82162

Disponível em: https://www.nucleodoconhecimento.com.br/saude/doenca-dekawasaki 
KENTSIS, A. et al. Urine proteomics for discovery of improved diagnostic markers of Kawasaki disease. EMBO Mol Med, v. 5, n. 2, p. 210-220, fev. 2013.

KIM, J. S.; KWON, S. H. Atypical Kawasaki disease presenting a retropharyngeal abscess. Braz J Otorhinolaryngol, v. 82, n. 4, p. 484-486, 2016.

LIU, M. Y. et al. Risk factors and implications of progressive coronary dilatation in children with Kawasaki disease. BMC Pediatrics, v. 17, n. 139, p. 1-7, jun. 2017.

MAGALHÃES, C. M. E. Estudo da prevalência da perda auditiva neurossensorial como complicação da doença de Kawasaki. Tese (Doutorado em Ciências da Saúde) - Faculdade de ciências da saúde, Universidade Federal de Brasília, Brasília. 2008.

MAGALHÃES, C. M. R.; ALVES, N. R. M. Doença de Kawasaki. In: I. Burns, DAR, Campos Júnior D, Silva LR, Borges WG. Tratado de pediatria: Sociedade Brasileira de Pediatria. 4. ed. Barueri, SP: Manole, 2017. p.1825-1835.

MARTíNEZ, U. M.; MÉNDEZ, F. M. Manejo anestésico del paciente com enfermedad de Kawasaki durante la cirugía de revascularización coronaria: informe de um caso. Archivos de Cardiología de México, v. 83, n. 4, p. 267-272, abr. 2013.

MEHNDIRATTA, S. et al. A case of incomplete and refractory Kawasaki disease: Diagnostic and therapeutic challenges. The South African Journal of Child Health, v. 8, n. 1, p. 37-38, fev. 2014.

MUTLUER, F. O.; ÇELIKER, A. Comment on Ligature of the Left Main Coeonary Artery after Surgery in Kawasaki Disease: Case Report. Brazilian Journal of Cardiovascular Surgery, v. 34, n.3, p. 382, jul. 2019.

PHILIP, S. et al. Role of Antioxidants in Horse Serummediated Vasculitis in Swine: Potential Relevance to Early Treatment in Mitigation of Coronary Arteritis in Kawasaki Disease. Pediatrics and Neonatology, v. 58, n. 4, p. 328-337, fev. 2017.

RC: 82162

Disponível em: https://www.nucleodoconhecimento.com.br/saude/doenca-dekawasaki 
PRINTZ, B. F. Noncoronary Cardiac Abnormalities Are Associated With Coronary Artery Dilation and With Laboratory Inflammatory Markers in Acute Kawasaki Disease. Journal of the American College of Cardiology, v. 57, n. 1, p. 68-92, jan. 2011.

RODRIGUES, M. et al. Doença de Kawasaki e Complicações Cardiovasculares em Pediatria. Birth and growth medical jornal, v.27, n. 1, p. 54-58, fev. 2017.

ROSSI, F. S. et al. Extensa linfadenite cervical mimetizando adenite bacteriana como primeira manifestação da doença de Kawasaki. Einstein, v. 13, n. 3, p. 426429, jul./set. 2015.

ROWLEY, A. H. et al. Allograft Inflammatory Factor-1 Links T-Cell Activation, Interferon Response, and Macrophage Activation in Chronic Kawasaki Disease Arteritis. Journal of the Pediatric Infectious Diseases Society, v. 6, n. 3, p. 94102, set. 2017.

SCARDINA, G. A. et al. Oral necrotizing microvasculitis in a patient affected by Kawasaki disease. Medicina Oral Patologia Oral y Cirugia Bucal, v. 12, n. 8, p. 560-564, dez. 2007.

SOTELO, N.; GONZÁLEZ, L. A. Kawasaki disease: A rare pediatric pathology in Mexico Twenty cases report from the Hospital Infantil del Estado de Sonora. Archivos de Cardiologia de Mexico, v. 77, n. 4, p. 299-307, dez. 2007.

XIE, X. F. et al. Proteomics study of serum exosomes in Kawasaki disease patients with coronary artery aneurysms. Cardiology Journal, v. 26, n. 5, p. 584-593, fev. 2018.

YAP, C. Y.; LIN, L. H.; WANGI, N. K. An atypical presentation of Kawasaki disease: a 10- year-old boy with acute exudative tonsillitis and bilateral cervical lymphadenitis. CLINICS, v. 67, n. 6, p. 689-692, 2012. 
Enviado: Abril, 2021.

Aprovado: Abril, 2021.

RC: 82162

Disponível em: https://www.nucleodoconhecimento.com.br/saude/doenca-dekawasaki 